\title{
ANÁLISE BIOECONÔMICA DO SEQÜESTRO FLORESTAL DE CARBONO E DA DÍVIDA ECOLÓGICA: UMA APLICAÇÃO AO CASO DO RIO GRANDE DO SUL
}

\author{
BIOECONOMIC ANALYSIS OF CARBON FOREST SEQUESTRATION AND OF THE ECOLOGICAL \\ DEBT: AN APPLICATION TO THE CASE OF RIO GRANDE DO SUL
}

\author{
Valny Giacomelli Sobrinho ${ }^{1}$ Paulo Renato Schneider ${ }^{2}$
}

\begin{abstract}
RESUMO
Apesar das críticas, o Protocolo de Kyoto se tem constituído na principal ferramenta política para enfrentar a mudança climática. No entanto, o único de seus instrumentos que prevê a cooperação entre países industrializados e em desenvolvimento para mitigar as emissões de gases-estufa é o MDL (Mecanismo de Desenvolvimento Limpo). A modalidade florestal do MDL pressupõe que as plantações florestais (florestamento/reflorestamento) podem ajudar na remoção das emissões de dióxido de carbono (o gás-estufa mais representativo) e compensar a perda de florestas naturais. Este estudo se concentra, então, nesse proclamado trade-off. Uma análise bioeconômica, da qual se abstraem variáveis monetárias, é empregada para avaliar o seqüestro florestal de carbono no Rio Grande do Sul. A área florestal do Estado é repartida somente entre florestas nativas e plantadas. Se, de um lado, isso não permite analisar o desmatamento, de outro, esse fenômeno é desprezível no Estado. A repartição do solo é expressa por uma função que reflete a demanda por remoção de emissões. Sua contraparte é a função oferta de emissões que depende das taxas de crescimento econômico. Os resultados mostram como, em última análise, a sustentação do crescimento econômico está condicionada à situação ecológica (dívida, crédito ou equilíbrio) de um país ou região. Em cada cenário, confrontam-se as vantagens econômicas e ambientais das estratégias do MDL e da conservação de florestas naturais. No final, estima-se uma taxa de overshoot para a atividade florestal no Rio Grande do Sul ao longo dos últimos 40 anos aproximadamente. As estimativas sugerem que o MDL pode aliviar pressões ambientais somente onde se registre crédito ecológico, onde o endividamento ecológico já esteja em curso, o MDL não substitui a conservação das florestas nativas.
\end{abstract}

Palavras-chave: seqüestro de carbono; mecanismo de desenvolvimento limpo; estratégias de mitigação; modelos bioeconômicos.

\begin{abstract}
Though heavily criticized, the Kyoto Protocol has stood out as the key political tool in addressing climate change. However, one of the few instruments that allows industrialized and developing countries to cooperate towards mitigation of GHGs is CDM (Clean Development Mechanism). The underlying assumption of forestry CDM is that forest plantations (afforestation/ reforestation) might help remove carbon dioxide (the most representative GHG) emissions and compensate for the loss of natural forests. Therefore, this study focuses on this alleged trade-off. A bioeconomic analysis, which abstracts out money variables, is applied to assess carbon forest sequestration in Rio Grande do Sul. The state's forest area is split up into natural and planted forests only. On one hand, this does not allow to check out for deforestation; on the other hand, such a phenomenon is not remarkable in Rio Grande do Sul. The land use is taken into account by a function that works as the emission removal demand. On the other hand, the emission supply function depends on the economic growth rates. The results show that, eventually, the sustainability of economic growth hinges on a region's or country's ecological situation - namely, equilibrium, credit or debt. The economic and environmental advantages of each mitigation strategy - CDM and natural forest conservation - are crosschecked. A nearly 40-year-long overshoot rate is, after all, estimated for the forest sector in Rio
\end{abstract}

1. Economista, Dr., Professor do Departamento de Ciências Econômicas, Centro de Ciências Sociais e Humanas, Universidade Federal de Santa Maria, Rua Floriano Peixoto, 1750, Bairro Centro, CEP 97015-372, Santa Maria (RS).giacomelliv@yahoo.com.br

2. Engenheiro Florestal, Dr., Professor do Departamento de Ciências Florestais, Centro de Ciências Rurais, Universidade Federal de Santa Maria, Cidade Universitária "Prof. Mariano da Rocha Filho", Av. Roraima, 1000, Bairro Camobi, CEP 97015-900, Santa Maria (RS).paulors@smail.ufsm.br

Recebido para publicação em 6/02/2008 e aceito em 7/04/2008. 
Grande do Sul. The estimates suggest that CDM might help to relieve environmental stress only where ecological credit is reported. Where ecological debt is already on, CDM was found unable to compensate for conservation disregard.

Keywords: carbon sequestration; clean development mechanism; mitigation strategies; bioeconomic models.

\section{INTRODUÇÃO}

$\mathrm{Na}$ aurora do século XXI, o mundo experimenta uma nova divisão econômica: a que se estabelece entre detentores de biodiversidade e produtores de biotecnologia. Essa cisão, porém, não observa fronteiras nacionais nem regionais. Antes, ela irrompe por meio dos ecossistemas cujos limites naturais nem sempre obedecem a contornos geopolíticos.

No contexto das emissões de gases de efeito-estufa (GEE) e do Mecanismo de Desenvolvimento Limpo (MDL), definido pelo Protocolo de Kyoto, uma das estratégias biotecnológicas mais recentes consiste em plantar florestas como fossas de remoção para as emissões de carbono. Economicamente, esses sumidouros artificiais de carbono, sobretudo por meio de florestamento/reflorestamento, disputam o uso da terra com seus congêneres naturais (e.g., florestas nativas, manguezais, charcos, campos, matas, etc.), com a indústria extrativa florestal e com outras atividades econômicas concorrentes à conservação de recursos florestais (e.g., agricultura, pecuária, mineração, etc.). De maneira geral, pode-se dizer que a taxa a que o uso do solo mudará para substituir umas pelas outras depende: a) da demanda de mercado por fossas de carbono; b) da taxa intrínseca de crescimento biológico das espécies particularmente existentes em uma floresta plantada ou nativa; $c$ ) das taxas de retorno oferecidas por usos alternativos da terra, comparativamente às obtidas com o seqüestro florestal de carbono.

Embora se disputem as causas e conseqüências do efeito-estufa, a essência do problema ambiental reside, de uma maneira geral, nos impactos que o crescimento contínuo da escala da economia mundial tem acarretado ao meio ambiente (MUELLER, 2007). Na arena das negociações internacionais, atribuem-se aos mecanismos do Protocolo de Kyoto (tais como o MDL) as virtudes de um jogo em que só há vencedores (VILLAVICENCIO, 2004).

Servindo-se da flexibilidade geográfica, o MDL possibilita que regiões industrializadas reduzam suas emissões de GEE, aproveitando-se dos baixos custos de abatimento, normalmente observados nas regiões menos industrializadas. Estas, por sua vez, podem colher benefícios sociais, econômicos e ambientais tanto com o investimento estrangeiro direto quanto com a transferência de tecnologias limpas fomentados pelo MDL. Ao fim e ao cabo, a meta de redução de emissões é atingida ao menor custo possível para todos - em conformidade com um critério que se convencionou chamar "custo-efetividade".

A convergência de interesses econômicos e ambientais de países industrializados e em desenvolvimento é apresentada como a principal virtude do MDL. Entretanto um grupo de países ricos em florestas argumenta que não se conseguirá deter a destruição das florestas tropicais, a menos que se criem incentivos para os países que se abstiverem dessa prática. Esses países vêm tentando inserir, no Protocolo de Kyoto, a estratégia da proteção (conservação das florestas existentes e prevenção do desmatamento) como opção à estratégia da mitigação definida pelo MDL florestal. Entre 3 e 14 de dezembro de 2007, esse grupo se fez representar na 13 ${ }^{\mathrm{a}}$ Conferência das Partes (COP-13), em Bali, Indonésia, para convencer os 192 signatários do acordo climático de que evitar o desmatamento ou conservar as florestas naturais pode sair mais barato do que florestar ou reflorestar. Porém, nem mesmo dentro desse grupo, existe consenso a respeito. O Brasil, por exemplo, receia que um "programa de desmatamento evitado" sirva de pretexto para transformar suas florestas em propriedade internacional (THE ECONOMIST, 3/12/2007). Nesse caso, qualquer país poderia valer-se das florestas brasileiras - que ocupam praticamente metade do território nacional (SCHNEIDER et al., 2005b) - para receber os incentivos previstos pelo programa.

Por outro lado, o MDL tampouco satisfaz o Brasil. Ainda que tenha contribuído com um impulso decisivo durante a fase embrionária desse instrumento, o Brasil teme que o MDL termine favorecendo a inundação do mercado de créditos de carbono com excedentes de oferta obtidos por meio das florestas tropicais. O conseqüente aviltamento dos preços do crédito de carbono implodiria, ao final, o próprio mecanismo (THE ECONOMIST, 3/12/2007).

Embora o MDL represente uma nova modalidade de investimento estrangeiro direto, em essência, suas causas e efeitos certamente não divergem daqueles relacionados à mesma classe de fenômenos. Da 
economia internacional se sabe que qualquer investimento estrangeiro direto se vale da concorrência imperfeita no comércio mundial para, mediante a inovação tecnológica (biotecnológica, no caso do MDL), obter renda em mercados externos (SÖDERSTEN e REED, 1994). Freqüentemente, esse tipo de investimento dissimula a prática do "rentismo" (rent-seeking) - termo que designa a apropriação de ganhos econômicos não-resultantes do comércio nem da produção de riquezas, mas da manipulação do ambiente de negócios (LOHMANN, 2006).

Ainda que os aspectos distributivos do MDL não dominem a literatura sobre o tema, especula-se que os riscos desse tipo de investimento recaiam de maneira desigual sobre as partes envolvidas. A todo projeto dessa natureza, é inerente o risco de que a redução de emissões realizadas seja menor do que a inicialmente estimada. Outro risco é que, por se tratar de uma modalidade incipiente, o mercado de carbono experimente forte volatilidade de preços. Os custos e benefícios de um projeto de MDL são calculados com base no preço de mercado vigente para o carbono, no momento em que se negociou a remoção a ser realizada. Por conseguinte toda oscilação observada nos preços do carbono representa um risco financeiro para investidores e beneficiários desses projetos (VILLAVICENCIO, 2004).

$\mathrm{Na}$ realidade, a volatilidade de preços não se restringe à condição embrionária do mercado de carbono. Embora, a rigor, não se possa reduzir valor a dinheiro, toda a economia está submetida à métrica monetária e financeira. Nos primórdios, o dinheiro funcionava como equivalente geral, presidindo a troca física de mercadorias. Em fins do século XX, apenas 2,5\% das transações monetárias referiam-se a essa troca. As restantes $97,5 \%$ destinavam-se a operações financeiras, em que nenhuma troca física de mercadorias estava envolvida (BARTOLI, 1996). No comércio internacional, as transações especulativas determinadas por fluxos e estoques de capital em carteira explicavam boa parte dos negócios. Mais de dois terços do valor das transações referiam-se a fluxos de capital, não de bens e serviços (conta corrente) (WILLIAMSON, 1989).

Há décadas, a moeda e as finanças perderam seu vínculo com a riqueza real (BARTOLI, 1996). O avanço das tecnologias de informação não só contribuiu para desmaterializar os capitais quase que completamente, mas também para desligar a moeda e as finanças da produção e das trocas de bens e serviços. Os instrumentos financeiros não servem mais para canalizar os capitais em direção aos investimentos produtivos. Os rendimentos que as ações de certas companhias proporcionam na bolsa não têm nenhuma relação com os lucros realizados na produção nem com o valor real dessas empresas.

Apesar de tudo, a tradição econômica insiste em utilizar o denominador monetário para avaliar e comparar os diversos custos e benefícios envolvidos nas trocas. Muitos deles, contudo, referem-se a bens e serviços ambientais que não são transacionados no mercado (e.g., ar, ciclos biogeoquímicos globais, capacidade de assimilação de rejeitos, etc.). Por outro lado, inseri-los no mercado por meio de sua valoração monetária é atribuir-lhes uma comensurabilidade e uma comparabilidade só fracamente existentes. Os impactos ambientais, por exemplo, costumam ser expressos em unidades de medida (e.g., toneladas/ha, km, ppm, etc.) que não admitem comparação. Portanto reduzi-las a valores monetários consente com uma prática "ultramonetarista" que não só torna possível "comprar sem pagar e vender sem deter" (ALLAIS apud BARTOLI, 1996, p. 131), mas que também confia indevidamente nos preços monetários como indicadores de sustentabilidade de uma economia (ROMEIRO in MAY et al., 2003). Epistemologicamente, essa abstração extrema a que a sofisticação monetária e financeira tem, paradoxalmente, conduzido a economia constitui a fonte de inspiração deste estudo.

\section{METODOLOGIA}

Seu objetivo geral é avaliar o portfolio estratégico composto pelo MDL e pela conservação. Para tanto, efetua-se uma análise teórica preliminar do relacionamento entre os sistemas econômico e ecológico (análise bioeconômica), em particular no que diz respeito às trocas definidas pela economia humana entre a biosfera e a atmosfera. Subsidiariamente, a) elabora-se um modelo bioeconômico para analisar a compensação de emissões de GEE na atmosfera através do armazenamento biológico delas em florestas (biosfera); b) testa-se a eficácia do modelo para o caso do Rio Grande do Sul; c) determinam-se indicadoressíntese de impacto ambiental, resumidos em taxas anuais de crescimento econômico e percentual de overshoot.

Por paradoxal que pareça, a primeira providência metodológica é expurgar os preços (e demais 
variáveis) monetários(as) da análise. A existência embrionária do mercado de carbono tende a ser assediada por considerável volatilidade de preços. Em primeiro lugar, grandes projetos de redução de emissões podem levar muitos anos até começarem a funcionar. Além disso, nem as empresas, nem os países conhecem, geralmente, os benefícios e custos de redução de emissões dos outros. Assim, em virtude da inexistência de informações confiáveis sobre o grau de escassez dos créditos de emissão, as decisões correm o risco de se tornarem ineficientes economicamente (EHRHART $e \mathrm{SCHLEICH,} \mathrm{2005).} \mathrm{Por} \mathrm{último,} \mathrm{à} \mathrm{medida} \mathrm{que} \mathrm{as} \mathrm{metas}$ de emissão fiquem cada vez mais rígidas (IPCC, 2007), os preços dos créditos de carbono tendem a subir dramaticamente. Em conseqüência, medidas mais caras de redução de emissão se tornam economicamente viáveis. No entanto, tal como sucede com o "mal holandês", essa elevação de custos de redução se dissemina, retrai a demanda por créditos de carbono e, finalmente, derruba seus preços (EHRHART $e$ SCHLEICH, 2005). Quanto mais alta a freqüência com que se registrem essas oscilações, maior o descolamento entre os preços e a realidade da economia do carbono. A extensão desse afastamento depende da maneira como se consolidem os mercados de carbono. Será menor, se eles emergirem espontaneamente das necessidades de compradores e vendedores; maior, se eles se estabelecerem como resultado de uma ação política, motivada por vantagens comerciais (i.e., rentismo) (KAY apud LOHMANN, 2006).

$\mathrm{Na}$ teoria econômica, a análise bioeconômica se vincula à tradição pioneira representada pelo que Schumpeter (in SCHUMPETER, 1994) classifica como "análise real". Distinta da análise monetária (FISHER, 1984; SCHUMPETER in SCHUMPETER, 1994), sobre a qual prevaleceu até fins do século XVIII, a análise real parte do princípio de que todos os fenômenos essenciais da vida econômica podem ser descritos em termos de bens e serviços. Essencialmente neutra, a moeda não passa de um recurso técnico, semelhante a um "véu" a ser retirado, para conhecer-se o rosto por detrás (SCHUMPETER in SCHUMPETER, 1994; WACKERNAGEL e REES, 1996). Enquanto a análise real (ortodoxa) repousa no princípio da parcimônia, o princípio do dispêndio, por outro lado, embala a análise monetária (heterodoxa) (AMADO in SILVA, 1992). Nesta, entende-se que os gastos de uns são as rendas de outros. Obstruindo-se os primeiros, prejudica-se a economia. Naquela, ao contrário, a virtude reside na abstinência. Assim, enquanto a heterodoxia enaltece o consumo, a ortodoxia enaltece a poupança.

Bioeconomicamente falando, poupança significa obediência aos limites que a natureza impõe ao consumo (uso) dos recursos naturais renováveis. Noutras palavras, trata-se de explorá-los (colheita) a um ritmo tal que respeite a taxa natural de regeneração ou de assimilação dos ecossistemas. Assim, só se colhe ou se utiliza - a fração correspondente à produtividade natural do recurso.

Partindo dessa visão biológica da relação entre a economia e o meio ambiente, rejeita-se a proposição de que é ilimitada a capacidade dos ecossistemas de fornecerem recursos naturais e de absorverem resíduos e poluição gerados pelo sistema econômico (MUELLER, 2007). Conforme a intensidade de tais impactos, a resiliência (capacidade de recuperar-se das perturbações) do meio ambiente pode ser tão abalada que terminará comprometendo, irreversivelmente, a oferta de recursos naturais e de serviços ecológicos locais (MUELLER, 2007; NICCOLUCCI et al., 2007). O descompasso entre a oferta de biocapacidade e a demanda de capital natural necessária para satisfazer certo nível de consumo ("pegada ecológica") acarreta desequilíbrio ecológico. Quando a primeira é maior que a segunda, tem-se um cenário de "crédito ecológico"; do contrário, quando esta é maior que aquela, contrai-se "dívida ecológica" (WACKERNAGEL e REES, 1996; NICCOLUCCI et al., 2007).

A troca ecológica desigual (dívida ou crédito ecológicos) manifesta-se de duas formas: por meio dos preços internacionais ou por meio do "espaço ambiental" (MARTÍNEZ ALIER, 2002). No primeiro caso, os preços das mercadorias exportadas não incluem compensações monetárias pelos danos (custos) ambientais infligidos aos produtores. No segundo caso, o nível de consumo de alguns países ou regiões do globo implica um uso desproporcional do espaço ambiental (reservatórios naturais - atmosfera, biosfera, geosfera, hidrosfera e criosfera) e dos serviços ecológicos prestados aí.

Mesmo quando aplicada aos preços internacionais, a análise monetária se mostra inadequada para calcular a dívida (ou o crédito) ecológica(o). Nem todas as externalidades ambientais (custos e benefícios associados a impactos ambientais) ou a deterioração de recursos naturais podem ser quantificadas em moeda (MARTÍNEZ ALIER, 2002). Mais complicado ainda é que o valor monetário (preço) das mercadorias não está correlacionado ao seu conteúdo energético. O preço de um tapete persa é incomparavelmente maior que o de uma tonelada de carvão. Entretanto a quantidade de energia utilizada para extraí-la é certamente muito 
superior à que se empregou na fabricação do tapete. Quer dizer, nem sempre a mercadoria de maior valor monetário é a que contém maior quantidade de energia (AYRES, 2001 e 2004). Por razões semelhantes, nem sempre os preços monetários comunicam a escassez de bens e serviços ambientais (WACKERNAGEL $e$ REES, 1996). Logo, a análise monetária distorce - se não impossibilita - o cálculo da dívida (ou do crédito) ecológica(o).

É outra ilusão imaginar que a distorção desapareça com a substituição do reducionismo monetário pelo reducionismo energético ou físico. Pilhagens comerciais como a biopirataria, por exemplo, tampouco podem ser medidas com unidades de energia (MARTÍNEZ ALIER, 2002). O modelo Bioeconômico para Seqüestro Florestal de $\mathrm{CO}_{2}$ (modelo BESF), desenvolvido neste estudo, não emprega nenhum tipo de medida monetária. O único propósito metodológico disso, no entanto, é demonstrar que toda análise real de fenômenos econômicos pode prescindir perfeitamente da métrica da moeda. Não só porque os fenômenos ambientais exijam cada vez mais essa emancipação (MUNDA et al., 1994; MARTíNEZ ALIER et al., 1998; HOAG et al., 2002; MUNDA, 2004; MUNIER, 2006) mas também porque ela já foi considerada dentro da própria teoria econômica (SRAFFA, 1997; PATTERSON, 1998).

\section{Modelo Bioeconômico para Seqüestro Florestal de $\mathrm{CO}_{2}$ (BESF)}

Em sintonia com o método da "pegada ecológica" (ecological footprint), o modelo BESF analisa o balanço ecológico (equilíbrio, dívida ou crédito) do estado do Rio Grande do Sul, com base no uso estimado do espaço ambiental. Por isso emprega medidas de biomassa (MtC) que podem ser facilmente convertidas em medidas de área (ha ou $\left.\mathrm{km}^{2}\right)$. A quantidade de gás carbônico $\left(\mathrm{CO}_{2}\right)$ lançada na atmosfera pela economia em crescimento, ao longo de mais de três décadas (1970-2006), é utilizada para estimar que quantidade de carbono sólido $(\mathrm{C})$, retido na biomassa de florestas nativas e plantadas, seria necessária para absorver aquelas emissões. Desde que se saiba quanto de biomassa por unidade de área a floresta produz, pode-se determinar a extensão de terra $(\lambda)$ que as florestas deveriam ocupar para remover as emissões decorrentes do crescimento econômico $(k)$. Em suma, essa área indica o espaço ambiental que se demandaria para sustentar um dado nível de consumo de emissões (NICCOLUCCI et al., 2007).

Visto que as florestas naturais ocupam um espaço que, a rigor, não pode ser aumentado, quanto maior a área requerida, mais espaço se abre às plantações florestais (florestamento e/ou reflorestamento, contemplados pelo MDL). Todavia o modelo BESF não tem a ambição de examinar a conversão florestal em geral. Antes, ele se limita a analisar o trade-off essencial para o MDL: a compensação que se presume haver, quando se substituem florestas naturais por florestas plantadas. Para tanto, o modelo BESF supõe que a área florestal seja fixa. Logo, uma expansão das plantações florestais (MDL) implica necessariamente uma redução das florestas naturais e o conseqüente recuo da conservação. O movimento inverso não é admitido, em razão da premissa de que as florestas naturais não podem ser ampliadas.

Essa premissa, por sua vez, deriva da proposição de que os recursos naturais indispensáveis ao funcionamento do sistema econômico existem em quantidades limitadas, decrescentes com o uso. Esse declínio se deve à capacidade fixa - e normalmente baixa - com que os ecossistemas suportam os impactos das atividades econômicas (MUELLER, 2007). Esse conceito ecológico, contudo, não pode ser aplicado às sociedades humanas. Ao contrário de outras espécies, os humanos costumam suplantar os limites biofísicos por meio do comércio e da tecnologia (WACKERNAGEL e REES, 1996; MARTÍNEZ ALIER, 1998; MERICO, 2002; LEHTONEN, 2004; BRAGA et al., 2005).

Preocupado em estabelecer um limite $\left(K_{H}\right)$ para a poluição causada pela economia humana $\left(\hat{H}_{t}\right)$, o modelo BESF - basicamente um modelo de poluição - busca inspiração nos modelos da pesca - modelos econômicos para recursos naturais renováveis. O problema é que, nesses modelos, o limite é dado pela capacidade biológica de suporte, quando a taxa natural de crescimento da população atinge seu nível máximo. Essas determinações populacionais, contudo, são insuficientes, e impróprias até, para explicar as atividades humanas. Por isso o modelo BESF se vale das condições de eficiência econômica intertemporal entre as fossas ( $k_{j}=k$ ou taxas de crescimento/retorno uniformes) (COMMON, 1996) e de eficiência ecológica perfeita ( $\varepsilon=1$ ou tudo o que é emitido é removido) (AYRES, 2004) para estabelecer, idealmente, a capacidade bioeconômica de suporte $\left(K_{H}\right)$. Da curva de emissões restritas por esse limite, é que se deduz, então, a oferta de remoção $\left(\hat{G}\left(X_{t}\right)\right)$.

Nesse modelo, o equilíbrio ecológico é regulado pela taxa bioeconômica de câmbio $(\varepsilon)$. Essa taxa 
mostra como a modificação das relações espaciais (distribuição da remoção de carbono, $\lambda$ ) entre as fossas $j$ altera as relações temporais (taxas de crescimento econômico, $k$ ) dentro delas. Ecologicamente, a produção econômica nos novos espaços que se vão incorporando deixa de ser governada pelo tempo de reprodução da natureza. De um lado, a anexação de novos territórios acelera o tempo de produção econômica - tal como exigido pela circulação do capital (manufaturado e financeiro) e pela supremacia do presente, implícita na taxa de juros. De outro, opera-se, desse modo, uma destruição irreparável da natureza, à medida que os tempos geoquímico e biológico escapem ao controle da atividade econômica (MARTÍNEZ ALIER, 2002). Essa assincronia entre os ritmos da economia e da natureza redunda em um desequilíbrio ecológico crescente - normalmente, dívida ecológica (overshoot local) - que, no final, deprime ou aniquila o crescimento econômico (WACKERNAGEL $e$ REES, 1996). Portanto $\varepsilon$ informa a variação de $\lambda$ (desigualdade espacial) necessária para compensar variações em $k$ (desigualdade temporal) (Tabela 1).

\section{Pressupostos do modelo BESF}

a) Estoques florestais somente para seqüestro de carbono; não para colheita de madeira (KOOTEN et al. apud SEDJO $e$ MARLAND, 2003);

b) Fossas florestais: florestas plantadas $(x)$; florestas nativas $(y)$;

c) Remoção florestal: serviço comercializável intermediário (não-final);

d) Biotecnologias de produção: mitigação (MDL); conservação (FAO);

e) Matriz algébrica de transferência $t \times j$ ((NIEMANN, 1986; AMANN \& KLAASSEN, 1995; HUTTON \& HALKOS, 1995; ALTMAN et al., 1996; Tabela 1), que traduz a mecânica do modelo BESF (Figura 1).

f) Razão de biodiversidade $(\lambda)$ (Tabela 1): sua diminuição não significa desmatamento de florestas nativas, uma vez que isso acarreta penalidades legais; antes, deve-se interpretá-la como expansão do MDL, via SFM (Manejo Florestal Sustentável), que inclui, por exemplo, as técnicas de corte e manejo seletivos, períodos de rotação mais longos e as plantações protetoras para a provisão de serviços ambientais (FAO, 2004; IUCN $e$ WWF, 2004).

TABELA 1: Matriz algébrica de transferência.

TABLE 1: Transfer algebraic matrix.

\begin{tabular}{|c|c|c|c|c|c|}
\hline $\begin{array}{l}t \\
\text { períodos }\end{array}$ & $j$ fossas & remoção & $X$ & $Z$ & $\lambda$ \\
\hline 1 & $x_{1}$ & $y_{1}$ & $X_{1}=x_{1}+y_{1}$ & $Z_{1}=y_{1}-x_{1}$ & $\lambda_{1}=y_{1} \div x_{1}$ \\
\hline 2 & $x_{2}$ & $y_{2}$ & $X_{2}=x_{2}+y_{2}$ & $Z_{2}=y_{2}-x_{2}$ & $\lambda_{2}=y_{2} \div x_{2}$ \\
\hline$V$ & $V_{1}=x_{1}+x_{2}$ & $V_{2}=y_{1}+y_{2}$ & $V_{1}+V_{2}=X_{1}+X_{2}$ & $Z=Z_{1}+Z_{2}$ & $\lambda-1=Z \div V_{1}$ \\
\hline$M$ & $M_{1}=x_{2}-x_{1}$ & $M_{2}=y_{2}-y_{1}$ & $\begin{array}{c}M=M_{1}+M_{2} \\
M=X_{2}-X_{1}=\Delta X\end{array}$ & $\begin{array}{c}Z=Z_{1}+Z_{2} \\
Z=V_{2}-V_{1}=\Delta V\end{array}$ & $\lambda-1=Z \div V_{1}$ \\
\hline$i$ & $i_{1}=M_{1} \div x_{1}$ & $i_{2}=M_{2} \div y_{1}$ & $i=M \div X_{1}$ & \multirow{2}{*}{\multicolumn{2}{|c|}{$\varepsilon=M \div Z$}} \\
\hline$k$ & $k_{1}=1+i_{1}$ & $k_{2}=1+i_{2}$ & $k=1+i$ & & \\
\hline
\end{tabular}

Em que: $X=$ remoção total por período; $Z=$ exportações; $\lambda=$ razão de biodiversidade; $V=$ remoção total por fossa; $M=$ importações; $i=$ taxa bioeconômica de juro/crescimento econômico $(k=1+i) ; \varepsilon=$ taxa bioeconômica de câmbio. 


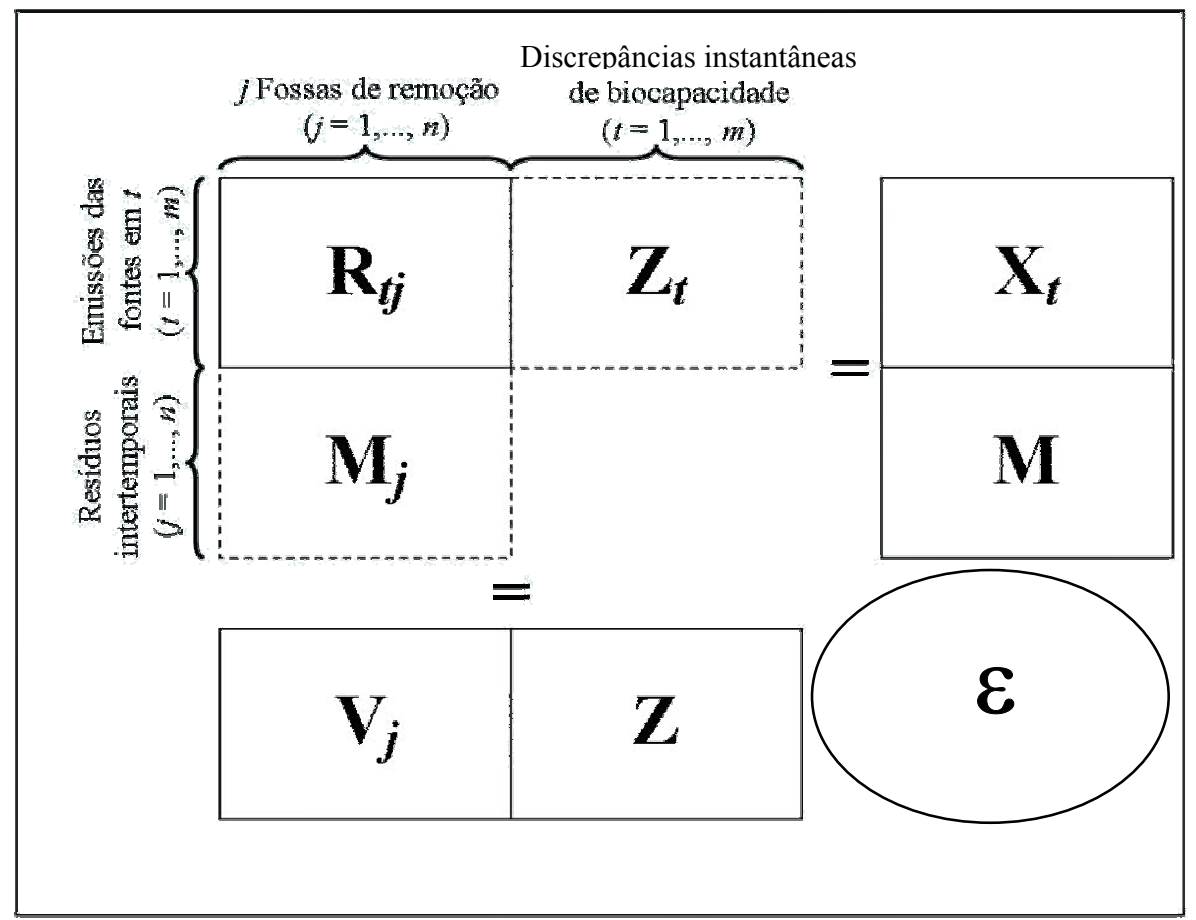

FIGURA 1: Mecânica do modelo BESF.

FIGURE 1: Mechanics of the BESF model.

\section{Funções}

Como se observa na Tabela $1, i=k-1$ depende de $M=\Delta X=X_{2}-X_{1}$, ao passo que $\lambda-1$ depende de $Z=\Delta V=V_{2}-V_{1}$. Portanto o equilíbrio da estrutura ilustrada na Figura 1 depende de:

$$
\varepsilon=\frac{\Delta X}{\Delta V}=\frac{(k-1) X_{1}}{(\lambda-1) V_{1}}
$$

Teoricamente, na Equação 1, $\Delta X$ pode simplesmente responder a qualquer taxa arbitrária de crescimento econômico $k$. Porém, na realidade, a preservação do equilíbrio ecológico $(\varepsilon=1)$ vai depender da desigualdade espacial existente ou possível $(\Delta V)$ na distribuição da remoção entre as fossas $j$. Em outras palavras, o crescimento econômico ao longo do tempo está condicionado ao perfil espacial de repartição da remoção. Assim é que a Macrobioeconomia se relaciona com a Microbioeconomia.

Do ponto de vista da distribuição espacial dos estoques nas fossas, $\lambda(\Delta V)$ está condicionada à remoção total realizada em cada período $\left(X_{t}\right)$ e ao longo do tempo $(Z)$. Por outro lado, do ponto de vista da distribuição temporal dos estoques nas fossas (Macrobioeconomia), a matriz de emissões-remoções (Tabela 1) é destituída de limites intrínsecos de variação para $k(\Delta X)$. Tais limites são fornecidos pela Microbioeconomia, por meio da função $\hat{G}\left(X_{t}\right)$.

\section{Função colheita de remoção $\left(\hat{H}_{t}\right)$}

A função oferta de remoção $\hat{G}\left(X_{t}\right)$ é, na verdade, uma função de demanda (ou colheita) restrita de remoção. Sua origem é a função de demanda (ou colheita) irrestrita de remoção $\left(\hat{H}_{t}\right)$, estimada a partir de dados observados para a relação entre crescimento econômico (PIB) e emissões de $\mathrm{CO}_{2}$ (Tabela 2). 
TABELA 2: Evolução do PIB (Y) e das emissões de $\mathrm{CO}_{2}$ (Q) no Brasil (1970-2005).

TABLE 2: Evolution of the GDP (Y) and $\mathrm{CO}_{2}$ emissions (Q) in Brazil (1970-2005).

\begin{tabular}{|c|c|c|c|c|c|c|c|}
\hline \multirow{5}{*}{$\begin{array}{c}\mathrm{t} \\
(\text { períodos})\end{array}$} & \multicolumn{5}{|c|}{ Brasil } & \multicolumn{2}{|c|}{ Rio Grande do Sul } \\
\hline & \multicolumn{2}{|c|}{ Emissões de $\mathrm{CO}_{2}$} & \multicolumn{2}{|l|}{ PIB } & \multirow{4}{*}{$\begin{array}{c}\text { PIB } \\
\text { florestal } \\
{ }^{\mathrm{d}} Y_{f} \\
(4 \% \mathrm{Y}) \\
\text { US\$ } 10^{9}\end{array}$} & \multirow{2}{*}{$\begin{array}{l}\text { Emissões de } \\
\qquad \mathrm{CO}_{2} \\
{ }^{\mathrm{e}} Q_{f}^{\mathrm{RS}}\end{array}$} & \multirow{4}{*}{$\begin{array}{c}\text { PIB florestal } \\
{ }^{\mathrm{f}} Y_{f}^{R S} \\
\left(1,62 \% \mathrm{Y}_{\mathrm{f}}\right) \\
\text { US\$ } 10^{9}\end{array}$} \\
\hline & ${ }^{\mathrm{a}} Q$ & ${ }^{b} g(Q)$ & $Y$ & ${ }^{c} \mathrm{~g}(\mathrm{Y})$ & & & \\
\hline & & $\%$ & US\$ de 2000 & $\%$ & & & \\
\hline & ${ }^{\mathrm{g}} \mathrm{MtCO}_{2}$ & & US\$ $10^{9}$ & & & ${ }^{\mathrm{g}} \mathrm{MtCO}_{2}$ & \\
\hline & (A) & & (B) & & (C) & (D) & $(\mathrm{E})$ \\
\hline 1970 & $221.200,00$ & - & 161,30 & - & 6,45 & 206,58 & 0,104522 \\
\hline 1975 & $282.600,00$ & 5,0 & 249,32 & 9,1 & 9,97 & 319,62 & 0,161741 \\
\hline 1980 & $334.500,00$ & 3,4 & 369,74 & 8,2 & 14,79 & 473,20 & 0,239501 \\
\hline 1985 & $363.000,00$ & 1,6 & 420,37 & 2,6 & 16,81 & 537,95 & 0,272290 \\
\hline 1990 & $374.900,00$ & 0,7 & 457,34 & 1,7 & 18,29 & 584,77 & 0,296006 \\
\hline 1995 & $422.300,00$ & 2,4 & 532,76 & 3,1 & 21,31 & 680,20 & 0,344347 \\
\hline 2000 & $480.200,00$ & 2,6 & 596,91 & 2,3 & 23,88 & 760,51 & 0,385042 \\
\hline 2002 & $507.100,00$ & 2,8 & 614,95 & 1,5 & 24,60 & 783,79 & 0,396835 \\
\hline 2003 & $507.869,42^{\mathrm{h}}$ & 0,1 & 615,46 & 0,5 & 24,72 & $787,70^{\mathrm{h}}$ & 0,398819 \\
\hline 2004 & $550.847,18^{\mathrm{h}}$ & 4,1 & 647,47 & 5,2 & 26,01 & $828,63^{\mathrm{h}}$ & 0,419558 \\
\hline 2005 & $573.311,53^{\mathrm{h}}$ & 2,0 & 662,36 & 2,3 & 26,49 & $847,67^{\mathrm{h}}$ & 0,429208 \\
\hline
\end{tabular}

Em que: (a) Inclui emissões da biomassa. (b) $\mathrm{g}(\mathrm{Q})=$ taxa de crescimento das emissões de $\mathrm{CO}_{2}=\left\{\left\{\left\{1+\left[\left(Q_{\mathrm{t}}-Q_{\mathrm{t}}\right.\right.\right.\right.\right.$ $\left.\left.\left.\left.\left.{ }_{1}\right) / Q_{\mathrm{t}-1}\right]\right\}^{1 / \Delta t}\right\}-1\right\} \times 100$. (c) $\mathrm{g}(\mathrm{Y})=$ taxa de crescimento do PIB $=\left\{\left\{\left\{1+\left[\left(Y_{\mathrm{t}}-Y_{\mathrm{t}-1}\right) / Y_{\mathrm{t}-1}\right]\right\}^{1 / \Delta t}\right\}-1\right\} \times 100$. (d) $\mathrm{Y}_{\mathrm{f}}=\mathrm{PIB}$ florestal. Conforme a SBS (2001), o PIB florestal representa 4\% do PIB nacional (ou US\$ 21 bilhões em 2001). Supõese que essa representatividade se mantém ao longo dos anos. (e) $\mathrm{Q}_{\mathrm{f}}^{\mathrm{RS}}=$ emissões de carbono pelo setor florestal no Rio Grande do Sul (RS). Estimativas partindo da Equação 2. (f) $\mathrm{Y}_{\mathrm{f}}^{\mathrm{RS}}=\mathrm{PIB}$ florestal do RS. Média geométrica das participações relativas do PIB florestal gaúcho no PIB florestal nacional (anos de 1990, 1995, 2000 e 2004), de acordo com o IBGE/Sidra - Extração vegetal. (g) $1 \mathrm{Mt}=1$ megatonelada $=10^{6} \times 10^{3} \mathrm{~g}=10^{9} \mathrm{~g}=1 \mathrm{Gg}=1$ gigagrama. (h) Estimativas a partir da Equação 2. Fonte: ALVIM (2003).

Regredindo-se a coluna (A) sobre a coluna (B) da Tabela 2, chega-se a:

$$
\begin{array}{ccc}
\hat{Q}_{t}=0,004125 Y_{t}^{3}-4,409996 Y_{t}^{2}+1976,845915 Y_{t} \\
\mathrm{t}=23,797 & \mathrm{t}=-27,829 & \mathrm{t}=56,488 \\
0,0000 & 0,0000 & 0,0000
\end{array}
$$

A Equação 2 estima a relação entre emissões de $\mathrm{CO}_{2}(Q)$ e PIB $(Y)$ para o Brasil. Como não há dados disponíveis para o Rio Grande do Sul, utilizam-se os valores da coluna (E) da Tabela 2 para estimar, por meio da Equação 2, os valores da coluna (D) para o estado. Dividindo-se os valores da coluna (D) (Tabela 2) por 44/12 ou 3,67 (STERN, 2006), converte-se $\mathrm{MtCO}_{2}$ (gás carbônico) em MtC (carbono sólido). Os resultados são dispostos na Tabela 3.

Descrito em função do tempo, e não da renda (PIB), o consumo de estoques de remoção, disposto na última coluna da Tabela 3, apresenta a trajetória dada pela Equação 3 e ilustrada pela Figura 2. Essa trajetória demonstra que o consumo de remoção cresce cubicamente com a renda e através do tempo. $\mathrm{O}$ traçado cúbico, por sua vez, sugere que períodos em que o crescimento econômico (PIB) desacelera retraem o consumo de emissões; outros, em que o PIB volta a crescer, revigoram esse consumo.

O liame entre o comportamento da renda e a passagem do tempo pode ser encontrado na "teoria do consumo da renda permanente" (SACHS $e$ LARRAIN B., 2000; MILES $e$ SCOTT, 2005). Segundo ela, o consumo, visto de uma perspectiva dinâmica, depende não só da renda (real) atual mas também da renda (real) esperada no futuro. Assim, num cenário de crescimento econômico continuado, o consumo de remoção cresce com o tempo, à medida que a renda (PIB) aumente e à medida que a geração da renda nacional (PIB) implique o consumo de emissões. 


$$
\begin{gathered}
\hat{X}_{t(L P)}=1,438472 t^{3}-17,432771 t^{2}+81,311111 t \\
\mathrm{t}=4,218 \quad \mathrm{t}=-4,010 \quad \mathrm{t}=6,161 \\
0,0056 \quad 0,0070 \quad 0,0008
\end{gathered}
$$

TABELA 3: Consumo do estoque florestal de carbono no Rio Grande do Sul $\left(\mathrm{X}_{\mathrm{f}(\mathrm{t})}^{\mathrm{RS}}\right)$, no início de cada período (1970-2006).

TABLE 3: Consumption of the carbon forest stock in Rio Grande do Sul $\left(\mathrm{X}_{\mathrm{f}(\mathrm{t})}{ }^{\mathrm{RS}}\right)$, in the beginning of every period (1970-2006).

\begin{tabular}{c|c|c}
\hline $\mathrm{t}$ & $Q_{f}^{\mathrm{RS}}$ & $X_{f(\mathrm{t})}^{\mathrm{RS}}($ inicial $)$ \\
(períodos) & $\mathrm{MtCO}_{2}$ & $\mathrm{MtC}$ \\
\hline 1970 & 206,58 & 56,29 \\
1975 & 319,62 & 87,09 \\
1980 & 473,20 & 128,94 \\
1985 & 537,95 & 146,58 \\
1990 & 584,77 & 159,34 \\
1995 & 680,20 & 185,34 \\
2000 & 760,51 & 207,22 \\
2002 & 783,79 & 213,57 \\
2003 & 787,70 & 214,63 \\
2004 & 828,63 & 225,78 \\
2005 & 847,67 & 230,97 \\
2006 & - & 390,86 \\
\hline
\end{tabular}

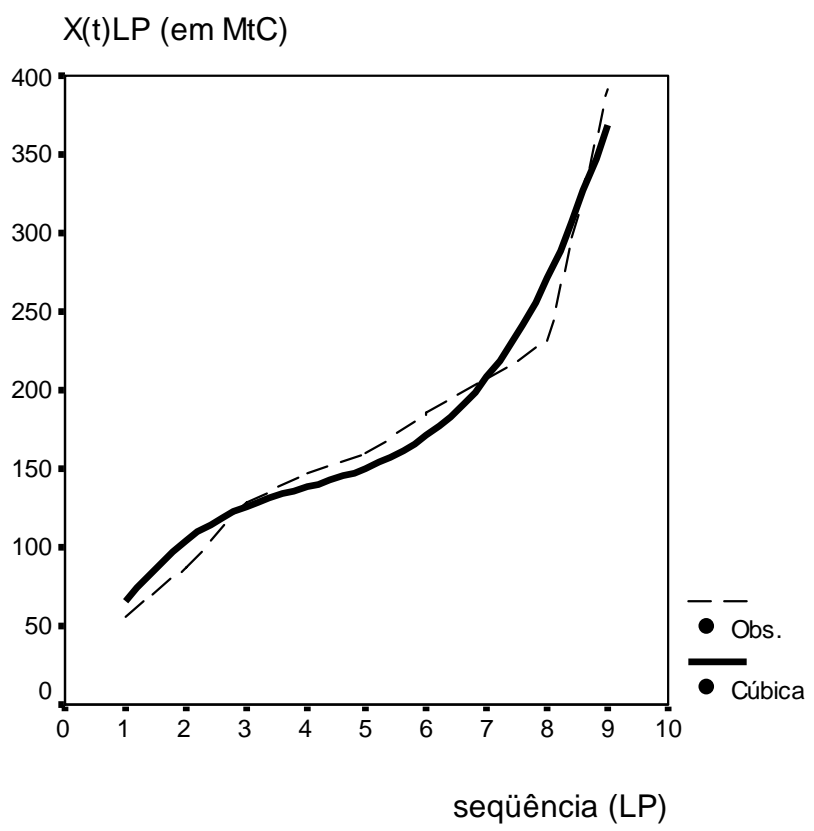

FIGURA 2: Consumo de remoção no Rio Grande do Sul ao longo do tempo (1970-2006).

FIGURE 2: Removal consumption in Rio Grande do Sul through time (1970-2006).

É de se esperar que, no longo prazo, essa renda e esse consumo não só permaneçam fortemente correlacionados mas também oscilem em torno de uma média tendencial. Embora desconhecida, essa média $\left(E\left(X_{t(L P)}\right)\right)$ (coluna $e$ da Tabela 4$)$ pode ser estimada, regredindo-se os valores da coluna (d) da Tabela 4 sobre os da coluna (a). O resultado dessa regressão é a Equação 4: 


$$
\begin{aligned}
& E\left(X_{t(L P)}\right)=X_{t}^{1,003670} \\
& \ln E\left(X_{t(L P)}\right)=1,003670\left(\ln X_{t}\right) \\
& \frac{\ln E\left(X_{t(L P)}\right)}{\ln X_{t}}=r=1,003670 \\
& \mathrm{t}=140,164 \\
& 0,0000
\end{aligned}
$$

\begin{tabular}{|c|c|c|c|c|c|c|c|}
\hline \multirow[b]{2}{*}{$t$} & \multirow[b]{2}{*}{ Qüinq. } & \multicolumn{3}{|c|}{ Quantidades observadas } & \multicolumn{3}{|c|}{ Estimativas $\left({ }^{\wedge}\right)$} \\
\hline & & $\begin{array}{c}\text { Inicial } \\
X_{t} \\
\text { (a) }\end{array}$ & $\begin{array}{c}\text { Final } \\
F\left(X_{t}\right) \\
\text { (b) }\end{array}$ & $\begin{array}{c}G\left(X_{t}\right) \\
(\mathrm{c}) \\
=(\mathrm{b})-(\mathrm{a})\end{array}$ & $\begin{array}{l}\text { Consumo de } \\
\text { remoção de } \\
\text { longo prazo } \\
\text { Eq. } 3 \\
X_{t(L P)}=f(t) \\
\text { (d) }\end{array}$ & $\begin{array}{l}\text { Consumo médio de } \\
\text { remoção } \\
\text { Eq.3 } \\
E\left(X_{t(L P)}\right)=f\left(X_{t}\right) \\
(\mathrm{e})\end{array}$ & $\begin{array}{c}\text { Colheita de } \\
\text { remoção } \\
\text { Eq. } 5 \\
H_{t}=E\left(X_{t(L P)}\right)-X_{t} \\
(\mathrm{f})=(\mathrm{e})-(\mathrm{a})\end{array}$ \\
\hline 1 & $1970-75$ & 56,29 & 87,09 & 30,80 & 65,32 & 57,13 & 0,84 \\
\hline 2 & $1975-80$ & 87,09 & 128,94 & 41,85 & 104,40 & 88,53 & 1,44 \\
\hline 3 & $1980-85$ & 128,94 & 146,58 & 17,64 & 125,88 & 131,26 & 2,32 \\
\hline 4 & $1985-90$ & 146,58 & 159,34 & 12,76 & 138,38 & 149,29 & 2,71 \\
\hline 5 & $1990-95$ & 159,34 & 185,34 & 26,00 & 150,55 & 162,33 & 2,99 \\
\hline 6 & $1995-00$ & 185,34 & 207,22 & 21,88 & 171,00 & 188,93 & 3,59 \\
\hline 7 & $2000-05$ & 207,22 & 230,97 & 23,75 & 208,37 & 211,32 & 4,10 \\
\hline 8 & $2005-06$ & 230,97 & 390,86 & 159,89 & 271,29 & 235,63 & 4,66 \\
\hline 9 & 2006 & 390,86 & & & 368,39 & 399,52 & 8,66 \\
\hline
\end{tabular}

TABELA 4: Estimativas do consumo de remoção partindo da remoção observada em cada período. TABLE 4: Estimates of the removal consumption from the observed removal in every period.

Por fim, a última coluna da Tabela 4 apresenta os resultados discretos da colheita de remoção em cada período. Regredindo-se esses valores (coluna $f$ ) sobre os da coluna (a), chega-se à função contínua de colheita de remoção $\left(\hat{H}_{t}\right)$ :

$$
\begin{gathered}
\hat{H}_{t}=0,006345 X_{t}^{1,213597} \\
\ln \hat{H}_{t}=\ln 0,006345+1,213597\left(\ln X_{t}\right) \\
\ln \hat{H}_{t}=-5,06008818+1,213597\left(\ln X_{t}\right) \\
\mathrm{t}=56,654 \\
0,0000 \\
\mathrm{t}=340,098 \\
0,0000
\end{gathered}
$$

\section{Função oferta de remoção $\left(\hat{G}\left(X_{t}\right)\right)$}

Quando se impõe um limite superior à função potência $\hat{H}_{t}$ (Equação 5), contém-se a demanda por remoção, e deixa-se de consumir estoques destinados a esse serviço. Tal restrição e abstinência implicam uma redução das importações de remoção $(M=\Delta X)$.

Para realizar essa contenção, é preciso, primeiro, encontrar uma taxa logística de variação $\left(g\left(v\left(X_{t}\right)\right)\right.$ para a colheita (consumo) de remoção $\left(\hat{H}_{t}\right)$. O problema é que essa taxa depende do limite máximo $\left(K_{H}\right)$ estabelecido para $\hat{H}_{t}$. O modelo BESF propõe que, em tese, esse limite de estoque pode ser determinado, simultaneamente, pelos ideais da eficiência econômica máxima (quando $k_{j}=k$ ) (COMMON, 1996) e da eficiência ecológica perfeita $(\varepsilon=1)$ (AYRES, 1999 e 2004). Quando as taxas de retorno deixam de ser discrepantes $\left(k_{j}=k\right)$, a conservação (investimento em fossas florestais nativas) e a mitigação (investimento em plantio de fossas florestais) tornam-se indiferentes entre si. Quando, além disso, todo resíduo produzido é assimilado $(\varepsilon=1)$, os movimentos de alocação e redistribuição nas fossas interrompem-se definitivamente.

Conhecendo-se $\lambda$ para um período-base qualquer, pode-se, pela Equação 6, deduzida através de 
Álgebra Vetorial, encontrar o valor de $k$ que torna estável a sustentabilidade ecológica $(\varepsilon=1)$ e econômica $\left(k_{j}=k\right)$ do sistema. O nível futuro de estoque $X_{2}$ (Equação 7 ou o intervalo de tempo exigidos para se uniformizar $k$ representam o "custo bioeconômico" da sustentabilidade estável. Esse "custo" é que se denomina "capacidade bioeconômica de suporte". Não se trata tanto de uma "meta" a ser perseguida quanto de uma medida da "perda" a ser suportada.

$$
\begin{aligned}
& {\left[\begin{array}{cc}
1 & k^{-1} \\
k & 1
\end{array}\right]\left[\begin{array}{c}
x_{1} \\
-y_{1}
\end{array}\right]=\left[\begin{array}{l}
0 \\
0
\end{array}\right]} \\
& {\left[\begin{array}{cc}
1 & k^{-1} \\
k & 1
\end{array}\right]\left[\begin{array}{l}
x_{1} \\
y_{2}
\end{array}\right]=\left[\begin{array}{l}
X_{1} \\
X_{2}
\end{array}\right]}
\end{aligned}
$$

Conhecendo-se $k$, podem-se, pela Equação 7, determinar $y_{2}$ e $X_{2}$. Substituindo-se o valor de $X_{2}$ na Equação 5, chega-se a $K_{H}$. Para, enfim, encontrar-se $g\left(v\left(X_{t}\right)\right)$ - a taxa logística de variação de $\hat{H}_{t}-$, utiliza-se $K_{H}$ no seguinte problema de otimização:

Função-objetivo:

$$
\operatorname{MIN} \sum_{t} S_{t}=\sum_{t}\left\lfloor g\left(v\left(X_{t}\right)\right)-\hat{H}_{t}\right\rfloor
$$

Restrições:

$$
\begin{gathered}
\hat{H}_{t}=0,006345 X_{t}^{1,213597} \\
g\left(v\left(X_{t}\right)\right)=\frac{1}{\frac{1}{K_{H}}+b_{0} b_{1}^{X_{t}}} \\
g\left(v\left(X_{t}\right)\right) \geq \hat{H}_{t}
\end{gathered}
$$

Em que, na Equação $8, S_{t}=$ saldos instantâneos entre a assimilação e a geração de emissões; na Equação $9, b_{0} \mathrm{e}$ $b_{1}=$ parâmetros da regressão logística.

A Equação 10 exige que a taxa de crescimento dos estoques para remoção não seja inferior ao consumo de remoção. Desenvolvido em GAMS-IDE 22.5 (Biodiversity.gms), o problema fornece como solução:

$$
g\left(v\left(X_{t}\right)\right)=\frac{1}{\frac{1}{160,373}+0,741 \times 0,994^{X_{t}}}
$$

A Equação 11 é a taxa logística que, aplicada à função potência $\hat{H}_{t}$ (Equação 5), a faz curvar para baixo. A curva resultante descreve a função de remoção $\left(\tilde{F}\left(X_{*}\right)\right.$, da qual se deduz a oferta de remoção $\left(\hat{G}\left(X_{t}\right)\right)$ (Figura 3, Tabela 5 e Equação 12). 


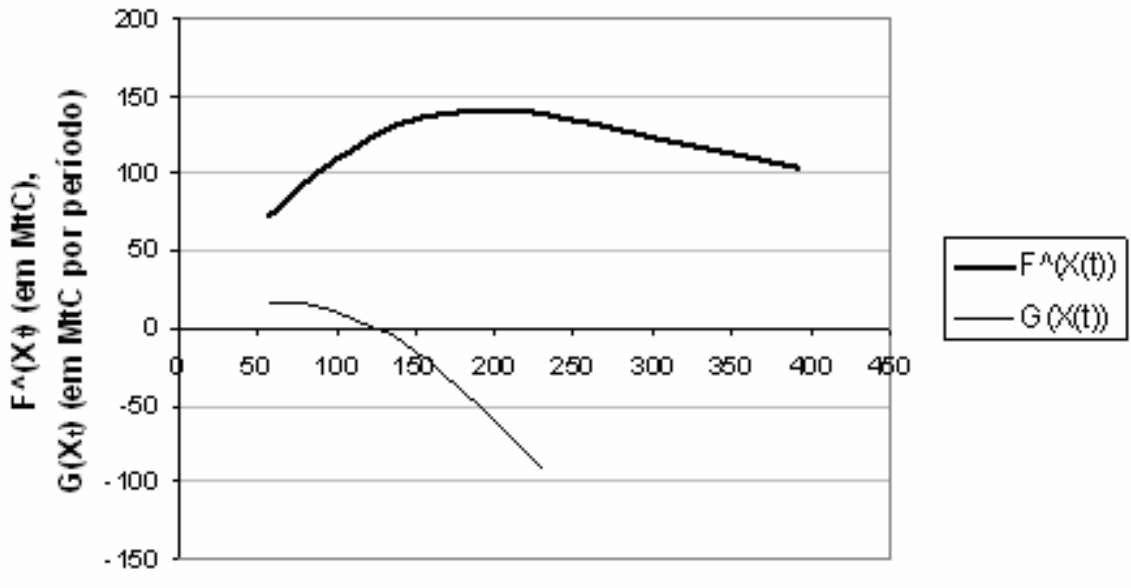

$X(t)(e m M t C)$

FIGURA 3: Microbioeconomia: função de remoção $\left(\boldsymbol{F}\left(\boldsymbol{X}_{\mathrm{r}}\right)\right)$ e a oferta de remoção $\left(\mathrm{G}\left(\mathrm{X}_{\mathrm{t}}\right)\right)$.

FIGURE 3: Microbioeconomics: removal function $\left(\hat{\boldsymbol{F}}\left(\boldsymbol{X}_{\boldsymbol{t}}\right)\right)$ and removal supply $\left(\mathrm{G}\left(\mathrm{X}_{\mathrm{t}}\right)\right)$.

TABELA 5: Estimação da função de remoção $\left(\mathrm{F}^{\wedge}\left(\mathrm{X}_{\mathrm{t}}\right)\right)$ e a oferta de remoção $\left(\mathrm{G}\left(\mathrm{X}_{\mathrm{t}}\right)\right)$.

TABLE 5: Estimation of the removal function $\left(\mathrm{F}^{\wedge}\left(\mathrm{X}_{\mathrm{t}}\right)\right)$ and the removal supply $\left(\mathrm{G}\left(\mathrm{X}_{\mathrm{t}}\right)\right)$.

\begin{tabular}{|c|c|c|c|c|c|c|c|}
\hline \multirow[b]{2}{*}{ Qüinq. } & \multirow[b]{2}{*}{$t$} & Obs. & \multicolumn{5}{|c|}{ Estimativas $\left({ }^{\wedge}\right)$} \\
\hline & & $\begin{array}{l}X_{t} \\
\text { (a) }\end{array}$ & $\begin{array}{l}\hat{\mathrm{H}}_{\mathrm{t}} \\
\text { Eq. } 5 \\
\text { (b) }\end{array}$ & $\begin{array}{c}\mathrm{g}\left(\mathrm{v}\left(\mathrm{X}_{\mathrm{t}}\right)\right) \\
\mathrm{Eq} .11 \\
(\mathrm{c})\end{array}$ & $\begin{array}{c}\vec{F}\left(X_{\mathrm{t}}\right)^{*} \\
(\mathrm{~d})=\mathrm{b}\left(K_{\mathrm{H}}-\mathrm{b}\right) / \mathrm{c}\end{array}$ & $\begin{array}{c}G\left(X_{t}\right) \\
(e)=(d)-(a)\end{array}$ & $\begin{array}{c}\hat{\mathrm{G}}\left(\mathrm{X}_{\mathrm{t}}\right) \\
\mathrm{Eq} .12\end{array}$ \\
\hline $1970-75$ & 1 & 56,29 & 0,845 & 1,872 & 72,00 & 15,71 & 14,45 \\
\hline $1975-80$ & 2 & 87,09 & 1,435 & 2,247 & 101,46 & 14,37 & 12,16 \\
\hline $1980-85$ & 3 & 128,94 & 2,310 & 2,879 & 126,78 & $-2,16$ & $-2,52$ \\
\hline $1985-90$ & 4 & 146,58 & 2,699 & 3,196 & 133,15 & $-13,43$ & $-12,69$ \\
\hline $1990-95$ & 5 & 159,34 & 2,987 & 3,445 & 136,42 & $-22,92$ & $-21,53$ \\
\hline 1995-00 & 6 & 185,34 & 3,588 & 4,014 & 140,12 & $-45,22$ & $-43,36$ \\
\hline 2000-05 & 7 & 207,22 & 4,108 & 4,563 & 140,68 & $-66,54$ & $-65,72$ \\
\hline 2005-06 & 8 & 230,97 & 4,686 & 5,241 & 139,19 & $-91,78$ & $-94,11$ \\
\hline 2006 & 9 & 390,86 & 8,874 & 13,030 & 103,16 & $-287,70$ & $-396,85$ \\
\hline ? & $\mathrm{EEF}^{\dagger}$ & 4244,35 & $160,373^{*}$ & 160,373 & 0,00 & $-4243,93$ & $-66479,99$ \\
\hline
\end{tabular}

Em que: $\left(^{*}\right) g\left(\hat{H}_{t}\right)=\hat{H}_{t}\left(K_{H}-\hat{H}_{t}\right) \times g\left(v\left(X_{t}\right)\right)$ e $\hat{F}\left(X_{s}\right)=g\left(\hat{H}_{t}\right) / g\left(v\left(X_{t}\right)\right)$. (†) EEF = estado estacionário para os fluxos, em que $\vec{F}\left(x_{r}\right)=0$. (†) $K_{\mathrm{H}}=160,373$.

$$
\begin{gathered}
\hat{G}\left(X_{t}\right)=-0,003802 X_{t}^{2}+0,470699 X_{t} \\
\mathrm{t}=-40,892 \quad \mathrm{t}=26,785 \\
0,0000 \quad 0,0000
\end{gathered}
$$

\section{Macrobioeconomia}

No agregado, a interação das funções demanda (Equação 5) e oferta (Equação 12) de remoção definem a macroescala ótima da bioeconomia da remoção. Enquanto a Equação 5 orienta-se por $k$, a Equação 12 depende indiretamente de $\lambda$. Portanto, em última análise, a escala bioeconômica é determinada por $k$ e $\lambda$.

A Tabela 1 e a Equação 1 mostram que $\varepsilon$ é a variável que relaciona $k$ e $\lambda$. Intuitivamente, percebe-se, então, que é preciso estimar $\varepsilon$ partindo de $k$ e $\lambda$ observados $(\varepsilon(k)$ e $\mathcal{E}(J))$ (Método I). Para estimar $\mathcal{E}(k)$, utiliza-se $\lambda$ de um período-base qualquer ou um valor de $\lambda$ que corresponda à média dos períodos. Com $\lambda$ fixo e $k$ disposto em ordem crescente, em vez de cronológica, observa-se como $\varepsilon$ e $k$ variam. Analogamente, para estimar $\tilde{E}(\lambda)$, mantém-se fixo o $k$ de um período-base qualquer (ou o $k$ médio para os períodos examinados), enquanto se observam, por ordem crescente de $\lambda$, as variações em $\varepsilon$ e $\lambda$. Desse modo, 
consegue-se estimar $\boldsymbol{\varepsilon}(k)$ e $\boldsymbol{\varepsilon}(\lambda)$ para a série de períodos considerados. A seguir, invertem-se essas funções, para chegar-se, afinal, aos valores estimados de $k(\hat{k})$ e $\lambda(\hat{z})$, partindo dos valores estimados de $\varepsilon(\hat{\varepsilon})$ (Método II).

No Rio Grande do Sul, $\lambda=10,859$ só é conhecido para o período-base $(t=9$, na Tabela 4 e na Tabela 5), mas $k$ pode ser calculado partindo dos $X_{t}$ observados $\left(k_{t}=X_{t} \div X_{t-1}\right)$. Aplicando-se o Método I e o Método II, recém-descritos, a esses dados, obtém-se:

$$
\begin{gathered}
\hat{k}_{t}=0,997209 e^{1,703281 \hat{\varepsilon}_{t}} \\
\hat{k}_{t}=0,997209 \exp \left(1,703281 \hat{\varepsilon}_{t}\right) \\
\ln \hat{k}_{t}=-0,002795+1,703281 \hat{\varepsilon}_{t} \\
\mathrm{t}=\begin{array}{c}
38186,908 \quad \mathrm{t}=11316,901 \\
0,0000 \quad 0,0000
\end{array} \\
\hat{\lambda}_{t}=0,976712+\frac{0,675690}{\hat{\varepsilon}_{t}} \\
\mathrm{t}=77,980 \quad \mathrm{t}=30,927 \\
0,0000 \quad 0,0000
\end{gathered}
$$

Reunindo-se as curvas descritas pelas Equações 13 e 14 ao longo do período que se estende de 1970 a 2006, chega-se à Figura 4. Por cálculo numérico (BARROSO et al., 1987) e com o auxílio do modelo Macrobioeco.gms, desenvolvido em GAMS-IDE 22.5, encontram-se os valores de equilíbrio para cada variável e cenário relevantes (Tabela 6).

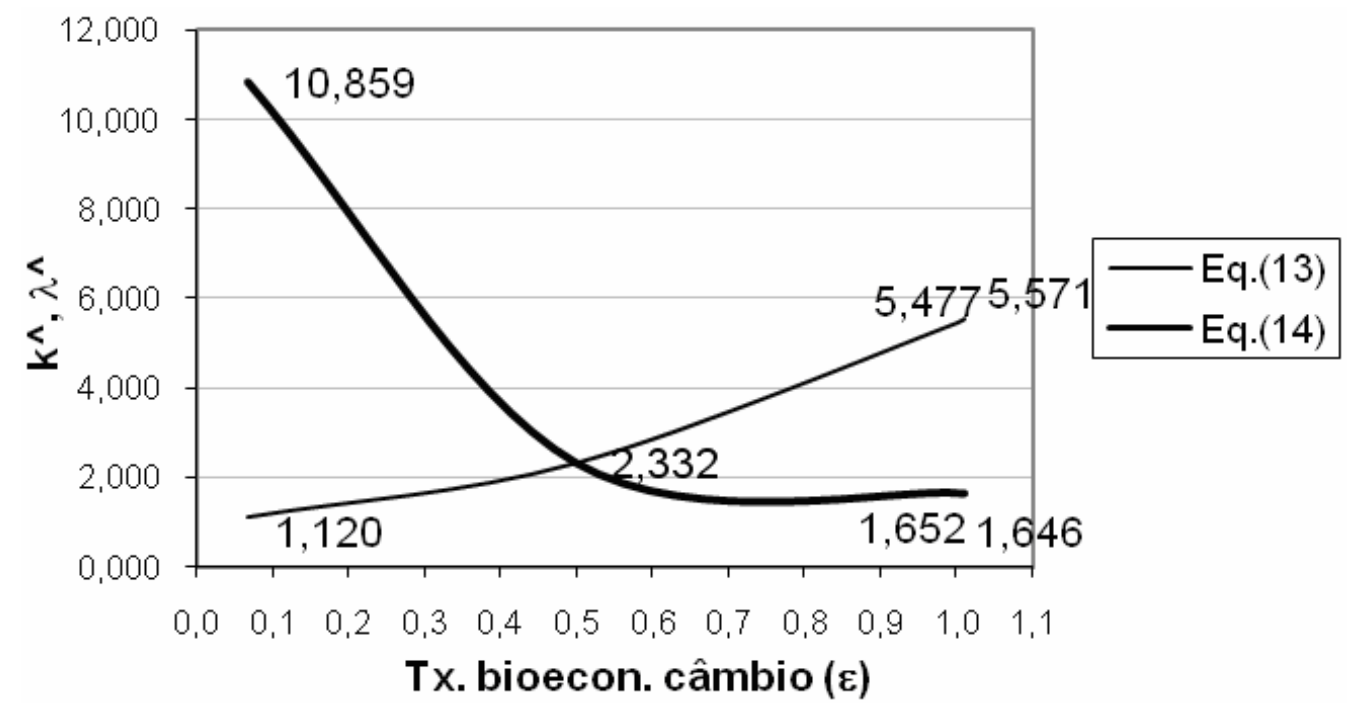

FIGURA 4: Equilíbrios macrobioeconômicos para a atividade florestal no Rio Grande do Sul (1970-2006). FIGURE 4: Macrobioeconomic equilibria for the forest activity in Rio Grande do Sul (1970-2006). 
TABELA 6: Cenários macrobioeconômicos para a atividade florestal no Rio Grande do Sul (1970-2006). TABLE 6: Macrobioeconomic scenarios for the forest activity in Rio Grande do Sul (1970-2006).

\begin{tabular}{l|c|c|c}
\hline \multicolumn{1}{c|}{ Cenários } & $\begin{array}{c}k(\varepsilon) \\
(\text { Eq. }(13)\end{array}$ & $\begin{array}{c}\lambda(\varepsilon) \\
\text { (Eq. }(14)\end{array}$ & $\varepsilon^{*} \cdot$ \\
\hline Período-base (BASE1) & 1,120 & 10,859 & 0,068 \\
Período-base (BASE2) & 1,6923 & 3,153 & 0,311 \\
Equil. Bioeconômico (BIOECO) & 2,332 & 2,332 & 0,499 \\
Equil. Ecológico (ECO) & 5,477 & 1,652 & 1,000 \\
Dívida Ecológica (DECO) & 5,571 & 1,646 & 1,010 \\
\hline
\end{tabular}

\section{Análise dos resultados}

A Figura 4 parece indicar que o Rio Grande do Sul ainda está muito distante de ingressar na região de endividamento ecológico. Porém, o desequilíbrio macrobioeconômico verificado no período-base (BASE) sugere que ou $\lambda=10,859$ observado é excessivo, ou $k=1,6923$ observado é muito intenso. Quando se mantém constante $\lambda=10,859$ (BASE1), resulta uma queda em $k=1,120$. Por outro lado, quando se mantém constante $k=1,6923$ (BASE2), também diminui $\lambda=3,153$ (Tabela 6). Portanto, a situação de crédito ecológico ilustrada pela Figura 4 talvez não seja tão confortável quanto pareça. Antes, pode estar havendo algum tipo de "ilusão ecológica", transmitida por uma taxa bioeconômica de câmbio muito apreciada $(0<\varepsilon$ $<1)$.

Para verificar isso, é preciso traduzir os resultados obtidos em termos de dois únicos indicadores: taxas anuais de crescimento econômico e percentual de overshoot. Assim, pode-se analisar se, ao longo dos últimos 35 anos, o crescimento da atividade florestal no Rio Grande do Sul comprometeu ou não a capacidade bioeconômica de suporte das florestas para remover as emissões de $\mathrm{CO}_{2}$ implicadas nessa expansão. Intuitivamente, é preciso reconstruir a trajetória de crescimento econômico do estado nos últimos 35 anos, como se as taxas bioeconômicas de câmbio (ع) vigentes em cada período fossem aquelas que otimizam o objetivo declarado de cada cenário. No cenário BIOECO, esse objetivo consiste em encontrar uma taxa bioeconômica de câmbio $\left(\varepsilon^{*}=0,499\right)$ tal que torne $\lambda=k$. No cenário $\mathrm{ECO}$, o objetivo é encontrar $\lambda$ e $k$ tais que assegurem $\varepsilon=1$.

A Tabela 7 revela que, no caso do Rio Grande do Sul, a combinação de equilíbrio macrobioeconômico $(\lambda=k)$ com crédito ecológico $(0<\varepsilon<1)$ (BIOECO) é mais danosa para a capacidade bioeconômica do que uma situação de desequilíbrio macrobioeconômico $(\lambda \neq k)$, mas com equilíbrio ecológico $(\varepsilon=1)(E C O)$. Portanto é bioeconomicamente mais eficiente manter o equilíbrio ecológico $(\varepsilon=1)$, em vez de utilizar o crédito ecológico $\left(0<\varepsilon^{*}=0,499<1\right)$ para "financiar" o equilíbrio bioeconômico $(\lambda=$ $k)$. 
TABELA 7: Cenários macrobioeconômicos ótimos (Tabela 6) para as florestas do Rio Grande do Sul (1970-2010).

TABLE 7: Optimal macrobioeconomic scenarios (Table 6) for Rio Grande do Sul's forests (1970-2010).

\begin{tabular}{|c|c|c|c|c|c|c|c|c|c|c|}
\hline $\begin{array}{l}\text { Bioeco }^{\#} \\
\text { Qüinq. }\end{array}$ & $\mathrm{t}$ & $X_{t}$ & $\begin{array}{c}\mathrm{b}=\mathrm{a} \div \\
\left(1+\lambda^{*}\right) \\
\text { Plant } \\
\mathrm{x}\end{array}$ & $\begin{array}{c}c=a-b \\
\text { Nat } \\
y\end{array}$ & $\begin{array}{c}\mathrm{d}=\mathrm{c}-\mathrm{b} \\
Z^{*}\end{array}$ & $\begin{array}{c}\mathrm{e} \\
\varepsilon^{*}=\text { cte. }\end{array}$ & $M^{*}$ & $\begin{array}{c}\mathrm{g}= \\
(\mathrm{a}+\mathrm{f}) \div \\
\mathrm{a} \\
k^{*}\end{array}$ & $\begin{array}{c}\mathrm{h}=\mathrm{g}^{1 / 5} \\
k^{*} \\
\text { (a.a.) }\end{array}$ & $\begin{array}{c}\mathrm{i}= \\
(\mathrm{h}-1) \\
\times 10^{2} \\
k^{*} \\
\text { \%a.a }\end{array}$ \\
\hline $70-75$ & 1 & 56,29 & - & - & - & - & - & - & - & - \\
\hline $75-80$ & 2 & 87,09 & 26,14 & 60,95 & 34,82 & 0,499 & 17,37 & 1,1995 & 1,0370 & 3,70 \\
\hline $80-85$ & 3 & 128,94 & 38,70 & 90,24 & 51,55 & 0,499 & 25,72 & 1,1995 & 1,0370 & 3,70 \\
\hline $85-90$ & 4 & 146,58 & 43,99 & 102,59 & 58,60 & 0,499 & 29,24 & 1,1995 & 1,0370 & 3,70 \\
\hline $90-95$ & 5 & 159,34 & 47,82 & 111,52 & 63,70 & 0,499 & 31,79 & 1,1995 & 1,0370 & 3,70 \\
\hline $95-00$ & 6 & 185,34 & 55,62 & 129,72 & 74,09 & 0,499 & 36,97 & 1,1995 & 1,0370 & 3,70 \\
\hline $00-05$ & 7 & 207,22 & 62,19 & 145,03 & 82,84 & 0,499 & 41,34 & 1,1995 & 1,0370 & 3,70 \\
\hline $05^{\dagger}-10$ & 8 & 390,86 & 117,30 & 273,56 & 156,25 & 0,499 & 77,97 & 1,1995 & 1,0370 & 3,70 \\
\hline \multicolumn{11}{|l|}{$\mathrm{Eco}^{+}$} \\
\hline $70-75$ & 1 & 56,29 & - & - & - & - & - & - & - & - \\
\hline $75-80$ & 2 & 87,09 & 32,84 & 54,25 & 21,41 & 1,000 & 21,41 & 1,2459 & 1,0449 & 4,49 \\
\hline $80-85$ & 3 & 128,94 & 48,62 & 80,32 & 31,70 & 1,000 & 31,70 & 1,2459 & 1,0449 & 4,49 \\
\hline $85-90$ & 4 & 146,58 & 55,27 & 91,31 & 36,04 & 1,000 & 36,04 & 1,2459 & 1,0449 & 4,49 \\
\hline $90-95$ & 5 & 159,34 & 60,08 & 99,26 & 39,17 & 1,000 & 39,17 & 1,2459 & 1,0449 & 4,49 \\
\hline $95-00$ & 6 & 185,34 & 69,89 & 115,45 & 45,57 & 1,000 & 45,57 & 1,2459 & 1,0449 & 4,49 \\
\hline $00-05$ & 7 & 207,22 & 78,14 & 129,08 & 50,95 & 1,000 & 50,95 & 1,2459 & 1,0449 & 4,49 \\
\hline $05^{\dagger}-10$ & 8 & 390,86 & 147,38 & 243,48 & 96,09 & 1,000 & 96,09 & 1,2459 & 1,0449 & 4,49 \\
\hline \multicolumn{11}{|l|}{$\begin{array}{l}\text { Deco- } \\
\text { MDL }^{\S}\end{array}$} \\
\hline $70-75$ & 1 & 56,29 & - & - & - & - & - & - & - & - \\
\hline $75-80$ & 2 & 87,09 & 42,90 & 44,19 & 1,29 & 12,680 & 16,32 & 1,1874 & 1,0349 & 3,49 \\
\hline $80-85$ & 3 & 128,94 & 63,52 & 65,42 & 1,91 & 12,680 & 24,16 & 1,1874 & 1,0349 & 3,49 \\
\hline $85-90$ & 4 & 146,58 & 72,21 & 74,37 & 2,17 & 12,680 & 27,47 & 1,1874 & 1,0349 & 3,49 \\
\hline $90-95$ & 5 & 159,34 & 78,49 & 80,85 & 2,35 & 12,680 & 29,86 & 1,1874 & 1,0349 & 3,49 \\
\hline $95-00$ & 6 & 185,34 & 91,30 & 94,04 & 2,74 & 12,680 & 34,73 & 1,1874 & 1,0349 & 3,49 \\
\hline $00-05$ & 7 & 207,22 & 102,08 & 105,14 & 3,06 & 12,680 & 38,83 & 1,1874 & 1,0349 & 3,49 \\
\hline $05^{\dagger}-10$ & 8 & 390,86 & 192,54 & 198,32 & 5,78 & 12,680 & 73,24 & 1,1874 & 1,0349 & 3,49 \\
\hline
\end{tabular}

(\#) $\lambda^{*}=2,332$. ( $\lambda^{*}=1,652$. (§) Cenário DECO intensivo em MDL, com $\lambda^{*}=1,030 . \mathrm{O}$ asterisco $(*)$ identifica os valores ótimos em cada cenário. (†) Final de período. 
TABELA 8: Taxa de overshoot por cenário florestal no Rio Grande do Sul (1970-2010) ${ }^{\circledR}$. TABLE 8: Overshoot rate by forest scenario in Rio Grande do Sul (1970-2010).

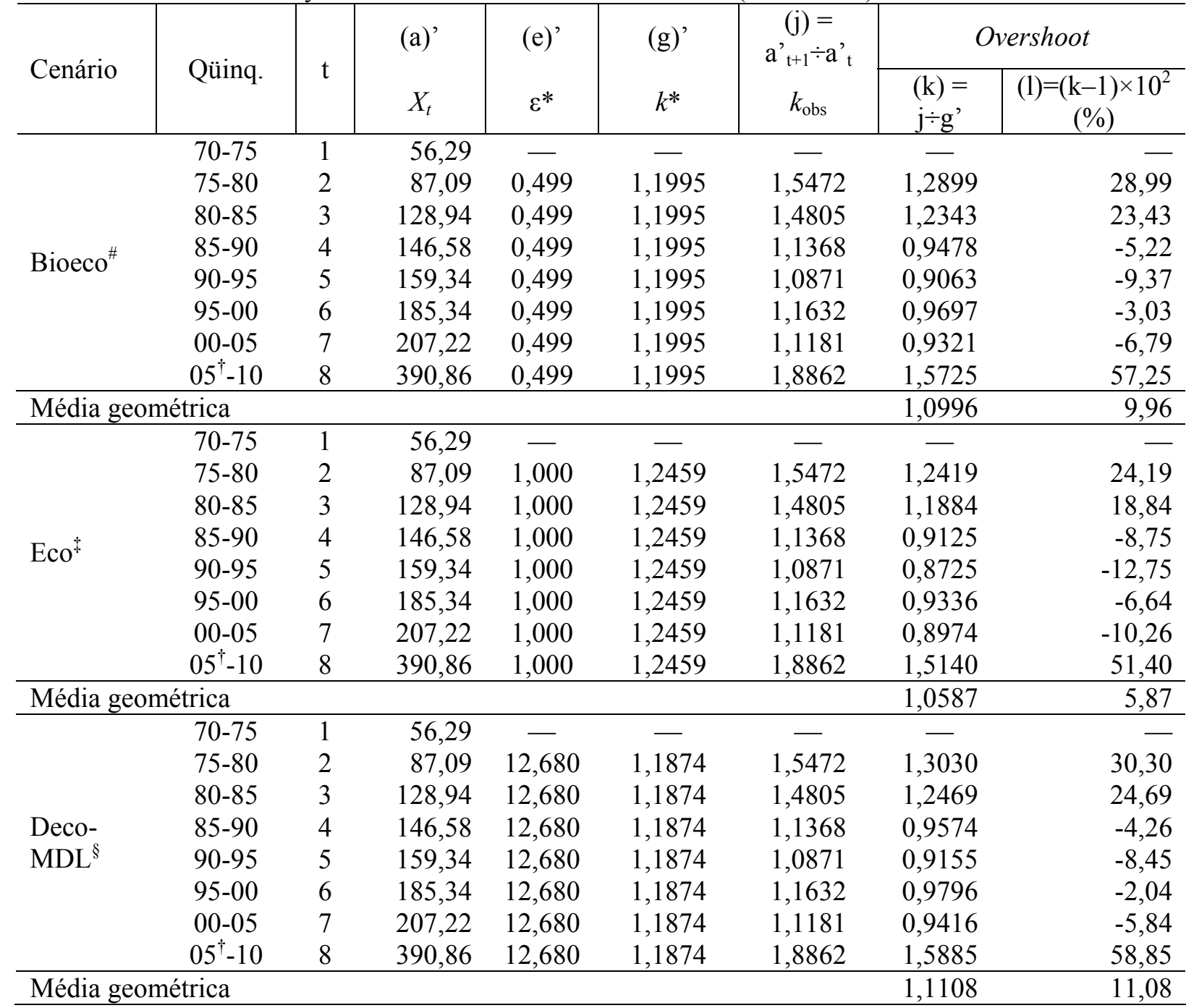

Em que: (@) O sinal diacrítico (') que aparece em algumas colunas desta tabela indica que elas foram transportadas da TABELA 7 , onde são identificadas com a mesma letra, porém sem o sinal. (\#) $\lambda^{*}=2,332$. ( $\ddagger$ ) $\lambda^{*}=1,652$. (§) Cenário DECO intensivo em MDL, com $\lambda^{*}=1,030$. (†) Final de período.

Por outro lado, quando a queda de $\lambda$ vai além da indicada pelo cenário ECO $\left(\lambda^{*}=1,652\right)$, delineia-se um quadro de endividamento ecológico (cenário DECO-MDL, com $\lambda^{*}=1,030$ e $\varepsilon=12,680$ ). Ou seja, prosseguindo-se com a expansão do MDL, ultrapassam-se os limites ecológicos - como indicado por $\varepsilon=12,680>1-$, e incorre-se em dívida ecológica (cenário DECO-MDL).

\section{CONCLUSÕES}

Esses resultados sugerem que a tecnologia do MDL não substitui a conservação da biodiversidade, salvo enquanto existir crédito ecológico. À medida que o MDL avance, rebaixando consideravelmente a proporção $(\lambda)$ entre a conservação e a mitigação, a dívida ecológica irromperá por meio de uma elevação abrupta de $\varepsilon$. No longo prazo, o efeito dessa pressão sobre a taxa bioeconômica de câmbio traduz-se por uma utilização excessiva da capacidade bioeconômica de suporte, apesar das taxas comparativamente menores de crescimento econômico. Quer dizer, a expansão desmedida do MDL aprofunda a dívida ecológica. Essa substituição imperfeita entre o MDL e a conservação limita o alcance da compensação sugerida pelo Tratado de Kyoto.

Por outro lado, a existência de crédito ecológico em uma região indica, necessariamente, a ocorrência 
de dívida ecológica em outra. O elevado valor de $\lambda$ no Rio Grande do Sul $(\lambda=10,859)$, no ano-base (cenário BASE1, na Tabela 6), sugere que o crescimento econômico do estado, nos últimos anos, tem, em alguma medida, se valido do endividamento ecológico de outras regiões. No estado, a proporção excessiva de florestas naturais em relação às florestas plantadas favorece um uso não-ótimo da capacidade bioeconômica de suporte. Biofisicamente, a alta densidade de carbono estocado nas árvores maduras das florestas nativas favorece maiores emissões no futuro, à medida que essas árvores morram.

Ao longo de quase quatro décadas, o mau aproveitamento (uso não-ótimo) do crédito ecológico no Rio Grande do Sul não só impôs dívida ecológica a outras regiões do país e/ou do exterior (e.g., países vizinhos), mas também proporcionou ao estado a oportunidade de beneficiar-se do MDL (cenário ECO da Tabela 7) até o ponto em que $\varepsilon=1$ (ausência de dívida ecológica). Se essa expansão não pressionar a capacidade bioeconômica de suporte a ponto de gerar dívida ecológica $(\varepsilon>1)$, pode-se reduzir a taxa de overshoot local para até quase $6 \%$ ao longo dos últimos 40 anos. Como suposto na metodologia, a redução de $\lambda$ indicada pelo cenário ECO (Tabela 6) não representa desmatamento, mas tão-só uma expansão do MDL por meio das técnicas de SFM.

\section{REFERÊNCIAS BIBLIOGRÁFICAS}

ALTMAN, A., AMANN, M., KLAASSEN, G., RUSZCZYŃSKI, A., SCHÖPP, W. Cost-effective sulphur emission reduction under uncertainty. European Journal of Operational Research, v. 90, p.395-412, 1996.

ALVIM, C. F. (coord.) Emissões energéticas 1970/2002. Economia e Energia, n. 41, nov.-dez. 2003. Disponível em: $<$ http://ecen.com >. Acesso em: 26 maio 2008.

AMADO, A. M. O real e o monetário em Economia: traços ortodoxos e heterodoxos do pensamento econômico. In: SILVA, M. L. F. (org) Moeda e produção: teorias comparadas. Brasília: Ed. da Universidade de Brasília, 1992. p. 285-314.

AMANN, M., KLAASSEN, G. Cost-effective strategies for reducing nitrogen deposition in Europe. Journal of Environmental Management, v. 43, p.289-311, 1995.

AYRES, R. U. The second law, the fourth law, recycling and limits to growth. Ecological Economics, v. 29, p. 473-483, 1999.

AYRES, R. U. Resources, scarcity, growth and the environment. Fontainebleau, France: Centre for the Management of Environmental Resources: INSEAD, 2001. 35p. (Working paper 97/13/EPS)

AYRES, R. U. On the life cycle metaphor: where ecology and economics diverge. Ecological Economics, v. 48, p. 425-438, 2004.

BARroso, L. C., BARroso, M. M. de A., CAMPos Filho, F. F., CARVAlho, M. L. B. de, MAiA, M. L. Cálculo numérico: com aplicações. 2.ed. São Paulo: Harbra, 1987.

BARTOLI, H. A economia, serviço de vida: crise do capitalismo, uma política de civilização. Lisboa: Instituto Piaget, 1996. (Coleção economia e política; 54)

BRAGA, B., HESPANHOL, I. CONEJO, J. G. L., MIERZWA, J. C., BARROS, M. T. L. de, SPENCER, M., PORTO, M., NUCCI, N., JULIANO, N., EIGER, S. Introdução à engenharia ambiental. 2.ed. São Paulo: Pearson Prentice Hall, 2005.

COMMON, M. S. Environmental and resource economics: an introduction. 2nd ed. New York: Longman, 1996.

EHRHART, K. -M., SCHLEICH, J. Comércio dos direitos de emissão. Scientific American Brasil, São Paulo, n. 12, p. 82-5, set. 2005. Edição especial.

FAO (Food and Agriculture Organization of the United Nations). Global forest resources assessment update 2005: terms and definitions (final version). Rome: Forest Resources Assessment Programme, 2004. (Working paper; 83/E)

FISHER, I. [1907] A teoria do juro: determinada pela impaciência por gastar renda e pela oportunidade de investi-la. São Paulo: Abril Cultural, 1984. 356p. (Os economistas)

GETTING SERIOUS IN BALI. The Economist, 3rd Dec. 2007. Disponível em: $<$ http://www.economist.com/world/international/displaystory.cfm?story_id=10237931> Acesso em: 03 dez. 2007.

HOAG, D. L., ASCOUGH II, J. C.; ENGLER-PALMA, A. The impact matrix approach and decision rules to enhance index dimensionality, flexibility and representation. Ecological Indicators, v. 2, p.161-168, 2002.

HUTTON, J. P., HALKOS, G. E. Optimal acid rain abatement policy for Europe: an analysis for the year 2000. Energy Economics, v. 17, n. 4, p. 259-275, 1995.

IBGE (Instituto Brasileiro de Geografia e Estatística). SIDRA: extração vegetal. Disponível em: $<\mathrm{http} / / /$ www.sidra.ibge.gov.br/bda/extveg/default.asp? $\mathrm{z}=\mathrm{t} \& \mathrm{o}=16 \& \mathrm{i}=\mathrm{P}>$. Acesso em: 26 maio 2008.

IPCC (Intergovernmental Panel on Climate Change). Climate change 2007: the physical science basis - summary for 
policy makers. In:

IPCC fourth assessment report: climate change 2007. Geneva, Switzerland: IPCC Secretariat: WMO, 2007.21p.

IUCN (The World Conservation Union), WWF (World Wildlife Fund). Changing realities: ecosystem approaches and sustainable forest management. Arborvitæ, Oct. 2004. 12p.

LEHTONEN, M. The environmental-social interface of sustainable development: capabilities, social capital, institutions. Ecological Economics, v. 49, p. 99-214, 2004.

LOHMANN, L. Carbon trading: a critical conversation on climate change, privatisation and power. Uppsala, Sweden: The Dag Hammarskjöld Centre: Corner House, Sept. 2006. (Development dialogue; 48)

MARTÍNEZ ALIER, J. Da economia ecológica ao ecologismo popular. Blumenau: Edifurb, 1998. (Coleção sociedade e ambiente; 2 )

MARTÍNEZ ALIER, J. The environmentalism of the poor: a study of ecological conflicts and valuation. Cheltenham, UK; Northampton, MA, USA: Edward Elgar, 2002.

MERICO, L. F. K. Introdução à economia ecológica. Blumenau: Edifurb, 2002. (Coleção sociedade e ambiente; 1)

MILES, D., SCOTT, A. Macroeconomia: compreendendo a riqueza das nações. São Paulo: Saraiva, 2005.

MUELLER, C. C. Os economistas e as relações entre o sistema econômico e o meio ambiente. Brasília: UnB: Finatec, 2007.

MUNDA, G. Métodos y procesos multicriterio para la evaluación social de las políticas públicas. Revista de la Red Iberoamericana de Economía Ecológica, v.1, p. 1-25, 2004.

MUNDA, G., NIJKAMP, P., RIETVELD, P. Qualitative multicriteria evaluation for environmental management. Ecological Economics, v. 10, p.97-112, 1994.

MUNIER, N. Economic growth and sustainable development: could multicriteria analysis be used to solve this dichotomy? Environment, Development and Sustainability, v.8, p.425-443, 2006.

NICCOLUCCI, V., PULSELLI, F. M., TIEZZI, E. Strengthening the threshold hypothesis: economic and biophysical limits to growth. Ecological Economics, v. 60 p. 667-672, 2007.

NIEMANN, B. L. Regional acid deposition calculations with the IBM PC Lotus 1-2-3 system. Environmental Software, v. 1, n. 3, p.175-181, 1986.

PATTERSON, M. G. Commensuration and theories of value in ecological economics. Ecological Economics, v. 25, p. 105-125, 1998.

ROMEIRO, A. R. Economia ou Economia Política da sustentabilidade. In: MAY, P. H., LUSTOSA, M. C., VINHA, V. da (orgs.). Economia do meio ambiente : teoria e prática. Rio de Janeiro : Elsevier, 2003. Introdução, p. 1-29.

SACHS, J. D., LARRAIN B., F. Macroeconomia: em uma economia global. São Paulo: Pearson Education do Brasil, 2000.

SBS (Sociedade Brasileira de Silvicultura). Estatísticas: setor florestal brasileiro. São Paulo, 2001. Disponível em: < http://www.sbs.org.br/estatisticas.htm >. Acesso em: 31 out. 2006.

SCHNEIDER, P. R., FLORIANO, E. P., SCHNEIDER, P. S. P., REINERT, D. J. FLOCEN - Plano estratégico de desenvolvimento florestal : Região Central do estado do Rio Grande do Sul. Santa Maria: FACOS/UFSM, 2005b.

SCHUMPETER, J. A. Value and money. In: University Press, 1994.1260 p. ch. 6, p. 276-334.

[1954] History of economic analysis. New York: Oxford

SEDJO, R. A., MARLAND, G. Inter-trading permanent emissions credits and rented temporary carbon emissions offsets: some issues and alternatives. Climate Policy, v. 3, p. 435-444, 2003.

SÖDERSTEN, B., REED, G. International economics. 3rd ed. London: MacMillan Press, 1994.

SRAFFA, P. [1960] Produção de mercadorias por meio de mercadorias: prelúdio a uma crítica da teoria econômica. São Paulo: Nova Cultural, 1997. 121p. (Os Economistas)

STERN, N. The economics of climate change: the Stern review. Cambridge, U. K.: Cambridge University Press: Cabinet Office - HM Treasury, 2006. Disponível em: $<\mathrm{http} / / / \mathrm{www} \cdot \mathrm{hm}-$ treasury.gov.uk/independent_reviews/stern_review_economics_climate_change/stern_review report.cfm $>$. Acesso em: 11 nov. 2006.

VILLAVICENCIO, A. Mitos y realidad del Mecanismo de Desarrollo Limpio. Revista de la Red Iberoamericana de Economía Ecológica, v. 1, 2004. Disponível em: <http://www.redibec.org/archivos/revibec.htm >. Acesso em: 08 jan. 2006.

WACKERNAGEL, M., REES, W. Our ecological footprint: reducing human impact on the Earth. Gabriola Island, BC, Canada: New Society Publishers, 1996. (The new catalyst bioregional series; 9)

WILLIAMSON, J. A economia aberta e a economia mundial: um texto de economia internacional. 3. ed. Rio de Janeiro: Campus, 1989. 